\title{
Nucleophilic Substitution Reactions of 2,4-Dinitrobenzene Derivatives with Hydrazine: Leaving Group and Solvent Effects
}

\author{
Mahmoud F. Ibrahim ${ }^{1}$, Hanaa A. Abdel-Reheem ${ }^{1}$, Sherine N. Khattab ${ }^{1} \&$ Ezzat A. Hamed $^{1,2}$ \\ ${ }^{1}$ Department of Chemistry, Faculty of Science, Alexandria University, Alexandria, Egypt \\ ${ }^{2}$ Department of Chemistry, Faculty of Science, Beirut Arab University, Beiurt, Lebanon \\ Correspondence: Ezzat A. Hamed, Department of Chemistry, Faculty of Science, Alexandria University, \\ Ibrahimia 21321, P.O. Box 426, Alexandria, Egypt. E-mail: ezzatah2@hotmail.com
}

$\begin{array}{lr}\text { Received: April 8, } 2013 & \text { Accepted: May 9, } 2013 \quad \text { Online Published: July 4, } 2013 \\ \text { doi:10.5539/ijc.v5n3p33 } & \text { URL: http://dx.doi.org/10.5539/ijc.v5n3p33 }\end{array}$

\begin{abstract}
The hydrazinolysis of 2,4-dinitrophenyl acetate in methanol proceed exclusively through acyl-oxygen scission by a concerted mechanism. The reaction of 1-chloro-2,4-dinitrobenzene with hydrazine in methanol, acetonitrile and dimethyl sulfoxide undergo uncatalyzed substitution and the formation of the zwitterionic intermediate is the rate-determining step. While 2,4-dinitrobenzene derivatives $\mathbf{1 , 2}, \mathbf{3}, \mathbf{4}, \mathbf{5 a - i ,} 6$ with hydrazine in DMSO undergo uncatalyzed substitution and the departure of the leaving group is the rate-determining step. The process depends on the basicity of the leaving group and its steric hindrance as well as the possible intramolecular hydrogen bond in the transition state. The reactivity of compounds $\mathbf{5 a - i}$ depends on the substituent of the thioaryl ring while the small $\rho_{\mathrm{Y}}$ value is due to the sulfides existing preferentially in the skew conformation. The small $\beta_{\lg }$ value $(-0.18, \mathrm{r}=0.99)$ indicated that the reaction of sulfides with hydrazine proceeds with advanced bond formation to the nucleophile and the bond cleavage proceed in a slow extent in the transition state.
\end{abstract}

Keywords: 2,4-dinitrobenzene derivatives, nucleophilic acyl substitution, nucleophilic aryl substitution, hydrazine, solvent effect, substituent effect, Hammett and Bronsted correlations

\section{Introduction}

The generally accepted mechanism for nucleophilic aromatic substitution (the $\mathrm{S}_{\mathrm{N}} \mathrm{Ar}$ mechanism) is an addition-elimination mechanism and involves the formation of a Meisenheimer type of intermediate (Terrier, 1991). The rate-limiting step is the formation of the intermediate, the expulsion of the leaving group, or the proton transfer process. Several properties of the nucleophiles (basicity, polarisability, degree of solvation, etc) or leaving groups more or less influence reactivity depending on the kind of interaction between nucleophile, leaving group, substrate and solvent (Isanbor \& Babatunde, 2009; Crampton et al., 2006; Crampton, Emokape, Isanbor, \& Mondal, 2005; Emokape \& Atasie, 2005; Macini, Fortunato, \& Vottero, 2004; Macini, Fortunato, Adam, Vottero, \& Terenzani, 2002; Bartoli \& Toddesco, 1977). In reactions in which bonds are broken, part of one reactant, the leaving group, becomes detached. Actually, one might expect that a good leaving group gives an increased rate of substitution, whatever substrate or nucleophile is involved. Therefore, the leaving group can determine reactivity in nucleophilic substitution in aromatic system. This has fostered the illusion that the leaving group ability depends upon the $\mathrm{p} K_{\mathrm{a}}$ of the conjugate acid of the leaving group and will affect the rate of reaction if the leaving group is involved in the rate-determining step (Paghaleh, Harifi-Mood, \& Gholami, 2011; Crampton, Emokape, \& Isanbor, 2007; Crampton, Emokape, Howard, Isanbor, \& Mondal, 2004; Crampton, Emokpae, Howard, \& Isanbor, 2004; Annulli, Mencareli, \& Stegel, 1983; Stirling, 1979). In fact, several years ago, Bunnett, Garbisch, and Pruitt (1957) strongly supported the hypothesis of a two-step pathway for nucleophilic aromatic substitution, using as a criterion the so-called "element-effect" i.e., the variation in the rate of substitution as a leaving group is varied. To gain further understanding of the mechanism for nucleophilic aromatic substitution, and in order to explain the mobility of the leaving groups and substituent containing leaving group, kinetic studies of hydrazinolysis of 2,4-dinitrobenzene derivatives 1, 2, 3, 4, 5a-i, 6 in DMSO are examined. 


\section{Method}

\subsection{Materials}

GR grade DMSO, $\mathrm{MeOH}$ and acetonitrile were spec pure and commercially available. The benzylamine nucleophile, GR grade, was used after distillation. GR grade, hydrazine $99 \%$ was used without further purification.

\subsection{Preparation of Substrates: 2,4-dinitrobenzene Derivatives 1, 2, 3, 4, 5a-i, 6}

\subsubsection{2,4-Dinittrophenyl Acetate 1}

2,4-Dinittrophenyl acetate 1 (Guanti, Dell'Erba, Pero, \& Cevasco, 1978) was prepared by refluxing 2,4-dinitrophenol with excess acetic anhydride for 3 hours. The reaction mixture was worked-up with water, extracted with methylene chloride and dried over anhydrous $\mathrm{MgSO}_{4}$, and the product was crystallized from methanol as pale yellow needles, m.p. $69-75^{\circ} \mathrm{C}$

\subsubsection{1-Chloro-2,4-dinitrobenzene 2}

1-Chloro-2,4-dinitrobenzene $\mathbf{2}$ is commercially available (BDH) and was recrystallised from methanol (m.p. $\left.48-50{ }^{\circ} \mathrm{C}\right)$.

\subsubsection{1-methoxy-2,4-dinitrobenzene 3}

2,4-Dinitrophenyl methyl ether 3 (Nyburg, Faerman, Prasad, Palleros, \& Nudelman, 1987) was prepared by stirring equimolar amounts of sodium dissolved in $10 \mathrm{ml} \mathrm{MeOH}$ and 1-chloro-2,4-dinitrobenzene at room temperature. The reaction mixture was worked-up with water and dried over anhydrous $\mathrm{MgSO}_{4}$. The product was isolated and crystallized from methanol as pale yellow needles in yield $81 \%$, m.p. $94-96^{\circ} \mathrm{C}$.

\subsubsection{2,4-Dinitrophenyl Phenyl Ether 4}

2,4-Dinitrophenyl phenyl ether 4 (Bernasconi \& Schmid, 1967) was prepared by stirring sodium metal in $10 \mathrm{ml}$ ether containing phenol, then etheral solution of 1-chloro-2,4-dinitrobenzene was added at room temperature (molar ratio 4:4:1 respectively). The reaction mixture was worked-up with dilute sodium hydroxide (30\%). The formed precipitate was filtered, dissolved in ether and dried over anhydrous $\mathrm{MgSO}_{4}$. The product was crystallized from methanol as pale yellow needles in yield $78 \%$, m.p. $144-145^{\circ} \mathrm{C}$.

\subsubsection{2,4-Dinitrophenyl Aryl Sulphide 5a-i and Sulphones 6}

2,4-Dinitrophenyl aryl sulphide 5a-i and sulphones 6 (Ahmed et al., 1989; Saad et al., 1991) were prepared through nucleophilic displacement reactions starting from 2,4-dinitrochlorobenzene and sodium salt of 4-substituted thiophenols in alcohols at room temperature. The precipitate was crystallised from methanol as a pale yellow needles, in yield $82 \%, 86 \%, 83 \%, 85 \%, 79 \%, 77 \%, 79 \%, 80 \%$, and $72 \%$ respectively.

The corresponding sulphone $\mathbf{6}$ was prepared by oxidizing the sulphides $\mathbf{5 a}$ with slight excess of the theoretically required amount of $\mathrm{H}_{2} \mathrm{O}_{2}$ in glacial acetic acid. The product was crystallized from methanol as pale .yellow needles in yield $88 \%$.

\subsubsection{Product Analysis}

A mixture of the desired compound $\mathbf{1}\left(\mathrm{X}=\mathrm{OCOCH}_{3}\right)(0.05$ mole $)$ and hydrazine $(0.5$ mole $)$ in methanol were stirred at room temperature. The formed precipitate was filtered, washed with cold methanol and recrystallised from methanol. Analysis of the products gave a mixture of 2,4-dinitrophenol and acetyl hydrazide. When a mixture of compounds 2-6 ( 0.05 mole) and hydrazine $(0.5$ mole $)$ in methanol were stirred at room temperature, work up gave 2,4-dinitrophenylhydrazine (Ahmad, Qureshi, \& Andrabi, 1995) as a sole product.

\subsection{Kinetic Measurements}

The reaction mixture was prepared by the transfer of $1 \mathrm{ml}$ of the substrate solution that gives a final concentration of $1 \times 10^{-4} \mathrm{M}$ to a $10 \mathrm{ml}$ measuring flask and the volume was completed by a given volume of absolute solvent (methanol and acetonitrile or dimethyl sulfoxide). The measuring flask and the stock solution of the amine were allowed to reach thermal equilibrium in a well stirred and thermostatic bath at the desired temperature $\pm 0.5{ }^{\circ} \mathrm{C}$. The reaction time started when the amines was mixed with the reaction mixture (final concentration of amine ranges from $2 \times 10^{-2}$ to $72 \times 10^{-2} \mathrm{M}$ ) and transfer quickly to a well thermostatic chamber containing the UV cell. The absorbance $A_{t}$ at the desired $\lambda$ was recorded at several time intervals depending on the reaction rate. The resultant change of absorbance with time was recorded by kinetic mode or time scan mode on UV-VIS Shimadzu 160-A spectrophotometer. Measurements were usually carried by following the increase of the reaction products absorbance with time at $\lambda=410 \mathrm{~nm}$ for the reaction of 1 with hydrazine, and at $\lambda=$ 
365-440 $\mathrm{nm}$ for the reactions of 2-6 with hydrazine in DMSO.

\section{Results and Discussion}

\subsection{Reactions of 2,4-dinitrophenyl Acetate 1 with Hydrazine in Methanol (MeOH)}

It has long been known that either the acyl-oxygen bond or aryl-oxygen bond of phenyl esters can be cleaved depending on (i) the structure of the ester (Kirsch, Clewell, \& Simon, 1968; Konasiewicz \& Maccoll, 1964), (ii) the nature of reagent (Guanti, Dell'Erba, Pero, \& Leandri, 1977; Guanti, Dell'Erba, \& Pero, 1975), (iii) the basicity of the leaving group anion from the ester compared to that of the attacking nucleophile, (iv) the nature of substituent in the non leaving or leaving group containing the ester (Guanti et al., 1977; Guanti et al., 1975), and (v) the relative "hardness" and "softness" of the reaction site and reagent (Fawzy, Senior, El-Atawy, El-Sadany, \& Hamed, 2011).

We studied the mechanism for the reaction of 2,4-dinitrophenyl acetate 1 with hydrazine in $\mathrm{MeOH}$ to examine the mode of scission whether through the CO-O or/and Ar-O bond scission pathways. The reaction in methanol proceed exclusively through acyl-oxygen scission rather than aryl-oxygen scission as indicated from the isolation and identification of acetate hydrazide, 2,4-dinitrophenoxide, Scheme 1. Furthermore, the exclusive acyl-oxygen fission is attributed to the fact that the departure of 2,4-dinitro-phenoxide is better than the acetate as a leaving group. This is consistent with the fact that acetic acid is a relatively stronger acid with $\mathrm{p} K_{\mathrm{a}}=9.57(\mathrm{MeOH})$ (Edwards \& Pearson, 1973), where 2,4-dinitophenol p $K_{\mathrm{a}}$ value is equal $7.83(\mathrm{MeOH})$ (Dawson et al., 1986).

The reactions of 1 with hydrazine obeyed pseudo-first-order rate constants $\left(k_{\mathrm{obs}}\right)$. The linear plot of $\mathrm{k}_{\mathrm{obs}} v s$. amine concentration indicated that there is no base-catalysis and the overall reactions follow the route given by Scheme 1. The large negative $\Delta S^{\#}$ value indicates a rigid transition state or great participation of methanol molecules in the activated complex, Table 1 .

Table 1. Second-order rate constants, $\mathrm{k}_{\mathrm{N}}\left(\mathrm{m} \mathrm{mol}^{-1} \mathrm{~s}^{-1}\right)$, for the reaction of 2,4-dinitrophenyl acetate $\mathbf{1}$ with hydrazine in methanol at different temperatures

\begin{tabular}{cccccccc}
\hline Amine $/ \mathrm{T}^{\circ} \mathrm{C}$ & 10 & 15 & 20 & 25 & 30 & $-\Delta \mathrm{S}^{\#} \mathrm{Jmol}^{-1} \mathrm{~K}^{-1}$ & $\Delta \mathrm{H}^{\#} \mathrm{kJmol}^{-1}$ \\
\hline Hydrazine & 11.50 & 12.11 & 12.69 & 13.28 & 13.81 & 228.89 & 6.44 \\
\hline
\end{tabular}

Menger and Smith (1972) suggested that the leaving group departs slowly in either a concerted mechanism, Scheme 1, pathway (a) or a stepwise mechanism, Scheme 1, pathway (b). They chose to favor a stepwise mechanism. However, our results could favor a concerted mechanism rather than a stepwise mechanism because i) intramolecular hydrogen bond is not preferred in polar solvents and the large negative $\Delta S^{\#}$ value are in the line with concerted mechanism or the break-down of the addition intermediate to the products is the rate determining step, (ii) the $\mathrm{p} K_{\mathrm{a}}$ of the conjugate acid of the leaving group (2,4-dinitrophenoxide ion) is 7.83 while the $\mathrm{p} K_{\mathrm{a}}$ value of hydrazine is 8.10 respectively (Hall, 1957). It is apparent that the basicity of the incoming amines and the basicity of the leaving group are approximately the same, Scheme 1, pathway (a). Therefore, we can propose that the hydrazinolysis of $\mathbf{1}$ in $\mathrm{MeOH}$ proceeds through a concerted mechanism with a transition state TS. 


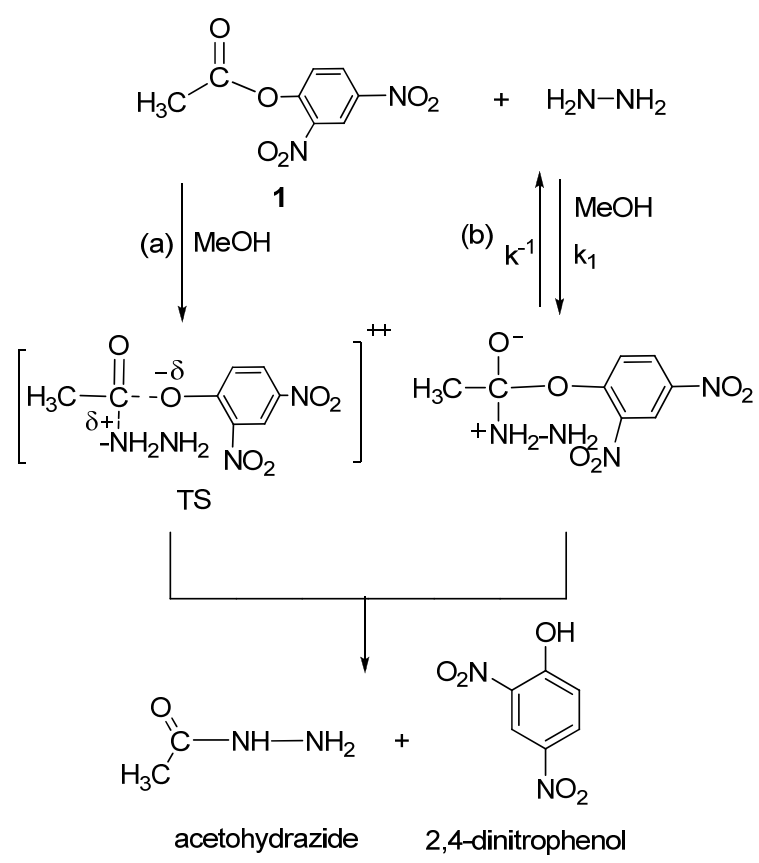

Scheme 1. The reaction possible mechanism of 2,4-dinitrophenyl acetate 1 with hydrazine in $\mathrm{MeOH}$

\subsection{Reactions of 1-chloro-2,4-dinitrobenzene 2 with Hydrazine in $\mathrm{MeOH}$, Acetonitrile (MeCN) and} Dimethylsulfoxide (DMSO) at Different Temperatures

Hydrazine $\left(\mathrm{N}_{2} \mathrm{H}_{4}\right)$ is known to be a moderately strong nucleophilic reagent toward 1-chloro-2,4-dinitrobenzene (Bunnett \& Davi, 1954, 1960). The reactions were followed spectrophotometrically by monitoring the appearance of the product 2,4-dinitrophenyl hydrazine at $\lambda=(365-440 \mathrm{~nm})$ depending on the solvent used, Scheme 2. The runs were designed to facilitate observation of pseudo-first-order kinetics (excess of hydrazine concentration).<smiles>[X]c1cc([NH+]=N)cc([N+](=O)[O-])c1[N+](=O)[O-]</smiles>

$$
\begin{aligned}
& \text { 2, } \mathrm{X}=\mathrm{Cl} \\
& \text { 3, } \mathrm{X}=\mathrm{OCH}_{3} \\
& \mathbf{4} \mathrm{X}=\mathrm{OPh} \\
& \text { 5a, } \mathrm{X}=\mathrm{SPh} \\
& \text { 6, } \mathrm{X}=\mathrm{SO}_{2} \mathrm{Ph}
\end{aligned}
$$<smiles>[X][14CH2]C[14C](=O)[O-]</smiles>

7

Scheme 2. Reactions of 1-chloro-2,4-dinitrobenzene $\mathbf{2 , 3 , 4 , 5 a , 6}$ with hydrazine at different temperatures

The pseudo-first-order rate constants $\left(\mathrm{k}_{\mathrm{obs}}\right)$ were determined from the slope of the linear plot of $\ln \left(\mathrm{A}_{\infty}-\mathrm{A}_{\mathrm{o}}\right)$ vs $\mathrm{t}$. All the plots of $\mathrm{k}_{\mathrm{obs}} v s\left[\mathrm{~N}_{2} \mathrm{H}_{4}\right]$ were linear passing through the origin suggesting that there is no base-catalysis and the reaction proceeds by uncatalysed process, Scheme 3 . The second-order rate constant $\left(\mathrm{k}_{\mathrm{A}}\right)$ was determined from the slope of the linear plots of $\mathrm{k}_{\text {obs }}$ vs $\left[\mathrm{N}_{2} \mathrm{H}_{4}\right]$. The $\mathrm{k}_{\mathrm{A}}$ and activation parameters $\Delta \mathrm{S}^{\#}$ and $\Delta \mathrm{H}^{\#}$ values are summarized in Table 2. The gross mechanism of this reaction in MeCN and DMSO is illustrated in Scheme 4. The application of the steady-state hypothesis to Scheme 3 gives Equation 1, where $\mathrm{k}_{\mathrm{A}}$ is the observed secondorder rate coefficient and the second hydrazine molecule can act as a base catalyst. 


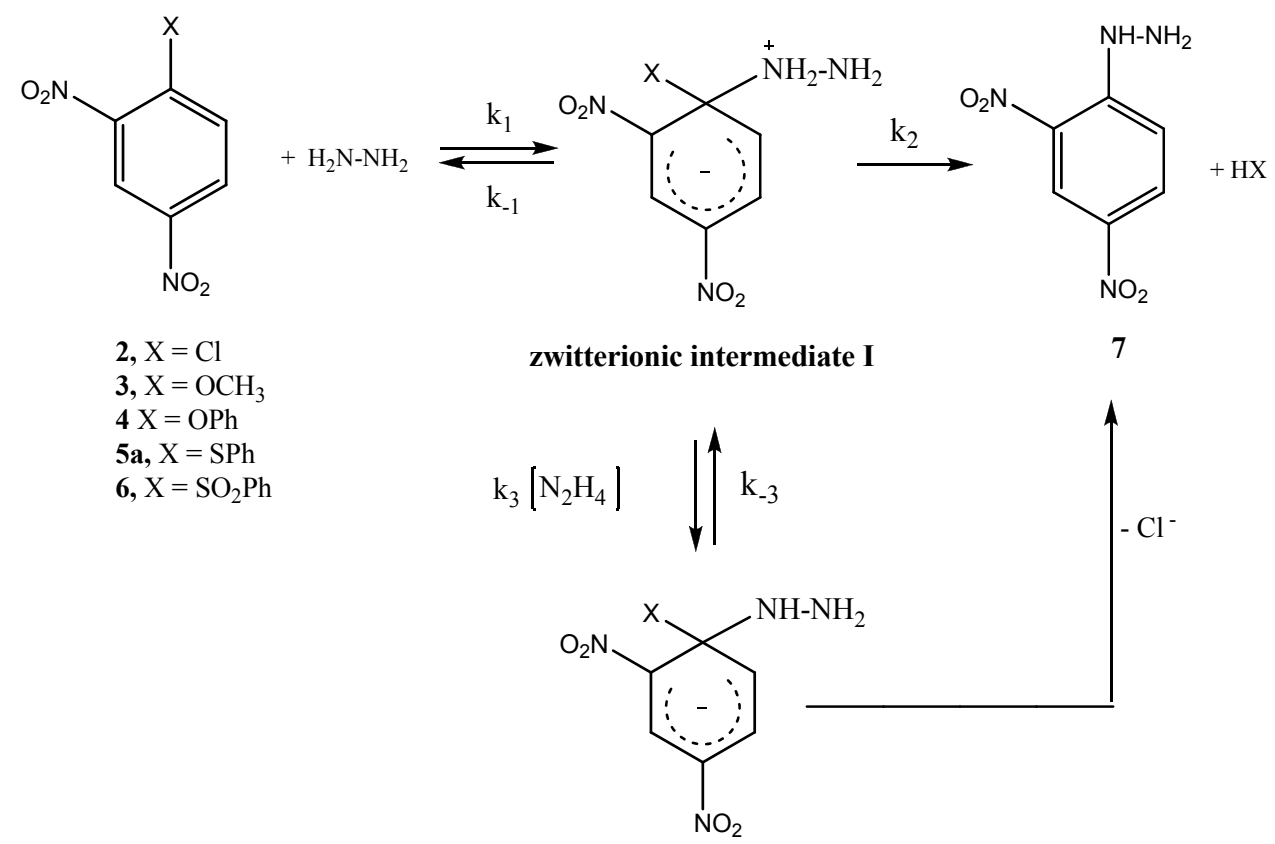

Meisenhiemer complex II

Scheme 3. The possible mechanism of the reaction of 1-chloro-2,4-dinitrobenzene $\mathbf{2 , 3 , 4 , 5 a , 6}$ with hydrazine at different temperatures

$$
\mathrm{k}_{\mathrm{A}}=\frac{k_{1}\left(k_{2}+k_{3}\left[N_{2} H_{4}\right]\right)}{k_{-1}+k_{2}+k_{3}\left[N_{2} H_{4}\right]}
$$

The lack of hydrazine catalysis and the good chloride leaving group means that $\mathrm{k}_{-1}<<\mathrm{k}_{2}+\mathrm{k}_{3}\left[\mathrm{~N}_{2} \mathrm{H}_{4}\right]$, then $\mathrm{k}_{\mathrm{A}}=\mathrm{k}_{1}$. This agrees with the rate determining formation of the zwitterionic intermediate I., Scheme 4. This is in line with the nucleophilic aromatic displacements of a good leaving group in polar and dipolar solvents (Khattab, Hamed, Albericio, \& El-Faham, 2011; El-Mallah, Nabil, Senior, Ramadan, \& Hamed, 2010; Asghar, Fathalla, \& Hamed, 2009; Fathalla, Kassem, \& Hamed, 2008; Khattab, Hassan, Hamed, \& El-Faham, 2007; Al-Howsaway, Fathalla, El-Bardan, \& Hamed, 2007; Fathalla \& Hamed, 2006; Fathalla, Ibrahim, \& Hamed, 2004; El-Hegazy, Abdel-Fathah, Hamed, \& Sharaf, 2000; Hamed, El-Bardan, Saad, Gohar, \& Hassan, 1997; Hamed, 1997a, 1997b). The plot of $\Delta \mathrm{H}^{\#}$ against $\log -\Delta \mathrm{S}^{\#}$ for the reaction of $\mathbf{2}$ with hydrazine in $\mathrm{MeOH}, \mathrm{MeCN}$ and DMSO gave straight line $(r=0.99)$ indicating a common mechanism for the reaction of $\mathbf{2}$ with hydrazine in these solvents.

Table 2. Summary of second-order rate constants and activation parameters values for the hydrazinolysis of $\mathbf{2}$ in $\mathrm{MeOH}$, $\mathrm{MeCN}$ and DMSO

\begin{tabular}{ccccccccccc}
\hline $\mathrm{T}^{\circ} \mathrm{C}$ & 10 & 15 & 20 & 25 & 30 & 35 & 40 & 45 & $\begin{array}{c}-\Delta \mathrm{S}^{\#} \\
\mathrm{~J} \mathrm{~mol}^{-1} \mathrm{~K}^{-1}\end{array}$ & $\begin{array}{c}\Delta \mathrm{H}^{\#} \\
\mathrm{~K} \mathrm{Jmol}\end{array}$ \\
\hline $\mathrm{MeOH}$ & - & - & - & 2.00 & 3.00 & 4.00 & 6.00 & 9.00 & 109.75 & 55.72 \\
$\mathrm{MeCN}$ & - & - & - & 42.00 & 52.00 & 63.00 & 76.00 & 91.00 & 178.00 & 27.79 \\
$\mathrm{DMSO}$ & 4853 & 5067 & 5259 & 5422.00 & - & - & - & - & 221.52 & 2.78 \\
\hline
\end{tabular}

\subsection{Effect of Solvent}

The reactivity sequence for the reactions of 2 with hydrazine is DMSO $>\mathrm{MeCN}>\mathrm{MeOH}$. In DMSO, the intramolecular hydrogen bonding to the o-nitro group is less significant since the $-\mathrm{NH}_{2}{ }^{+}$proton will be strongly hydrogen bonded to the DMSO solvent, Figure 1. In addition, $\mathrm{MeCN}$ molecules can stabilize the zwitterionic intermediate I by intermolecular hydrogen bonding as shown in Figure 2. In methanol, intramolecular hydrogen bond is relatively weak and the zwitterionic intermediate $\mathbf{I}$ is extensively solvated by intermolecular hydrogen 
bonding. Accordingly, the relative rates indicate that the intermolecular hydrogen bond may be the predominant effect in stabilizing the transition state consisting with the order mentioned before.

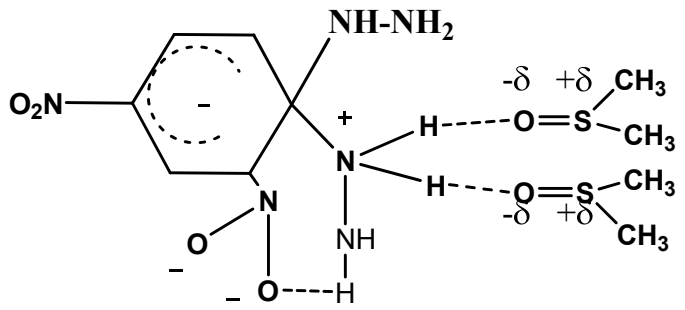

A

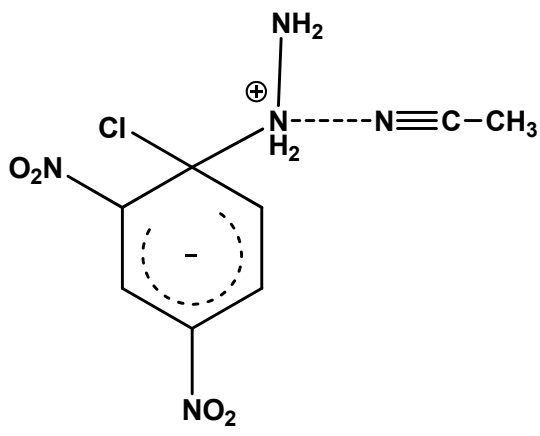

B

Figure 1. A) Strong hydrogen bonding of the $-\mathrm{NH}_{2}{ }^{+}$proton to DMSO. B) MeCN molecules stabilize the zwitterionic intermediate by intermolecular hydrogen bonding

A comparison of the $\Delta \mathrm{S}^{\#}$ and $\Delta \mathrm{H}^{\#}$ terms for the three solvents indicates that $\Delta H_{M e O H}^{\#}-\Delta H^{\#}{ }_{A N}=\Delta \Delta H^{\#}(27.93$ $\left.\mathrm{kJ} / \mathrm{mole}^{-1}\right), \Delta H_{A N}^{\#}-\Delta H_{D M S O}^{\#}=\Delta \Delta H^{\#}\left(25.01 \mathrm{~kJ} / \mathrm{mole}^{-1}\right) ; \Delta H_{M e O H}^{\#}-\Delta H_{D M S O}^{\#}=\Delta \Delta H^{\#}\left(52.94 \mathrm{~kJ} / \mathrm{mole}^{-1}\right)$; whereas $\mathrm{T} \Delta \mathrm{S}^{\#}$ is $68.25,43.52$ and $111.77 \mathrm{~kJ}$ mole $^{-1}$ for $\mathrm{MeOH}, \mathrm{MeCN}$ and DMSO respectively, Table 2. If $\mathrm{T} \Delta \mathrm{S}^{\#}$ is taken to reflect the stability of the zwitterionic intermediate, these values presumably indicate the possible existence of intramolecular hydrogen bond shown in Figure 2, in addition to the predominant intermolecular hydrogen bonding, Figures 1 and 2.

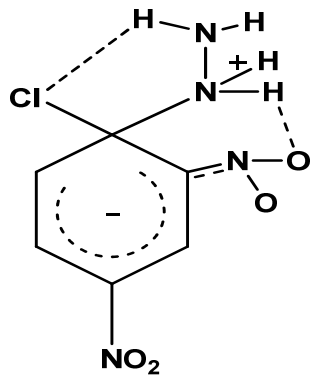

Figure 2. Intramolecular hydrogen bonding

\subsection{Reactions of 2,4-dinitrobenzene Derivatives with Hydrazine in DMSO (2, 3, 4, 5a, 6)}

Compounds 1-methoxy-2,4-dinitrobenzene 3; 2,4-dinitrophenyl phenyl ether 4; 2,4-dinitrophenyl phenyl sulfide 5a; and 2,4-dinitrophenyl phenyl sulfone $\mathbf{6}$ undergo attack of hydrazine molecule on the ipso carbon followed by the elimination of the leaving group anion $\left(\mathrm{X}={ }^{-} \mathrm{OMe},{ }^{-} \mathrm{OPh},{ }^{-} \mathrm{SPh},{ }^{-} \mathrm{SO}_{2} \mathrm{Ph}\right)$ as indicated from the isolation and identification of the known 2,4-dinitrophenyl hydrazine 7. All these reactions confirmed the pseudo-first order kinetics. The $\mathrm{k}_{\mathrm{obs}}$ values were determined from the slope of the plot of $\ln \left(\mathrm{A}_{\infty}-\mathrm{At}\right)$ vs. time. Generally five different concentrations of hydrazine were used to determine second-order rate constants. The linear plot of $\mathrm{k}_{\mathrm{obs}}$ vs hydrazine concentration passing through the origin, indicates that the general base catalysis by a second hydrazine molecule is absent. The apparent second-order rate constants $\mathrm{k}_{\mathrm{A}}$ determined in this way and the values of $\Delta \mathrm{H}^{\#}$ and $\Delta \mathrm{S}^{\#}$ for the reaction of hydrazine with 2-6 are summarized in Table 3. 
Table 3. Summary of second-order rate constants and activation parameters for hydrazinolysis of $\mathbf{2 ,}, \mathbf{3}, \mathbf{4}, \mathbf{5 a}, \mathbf{6}$ in DMSO

\begin{tabular}{ccccccc}
\hline $\mathrm{X}$ & $\mathrm{T}{ }^{\circ} \mathrm{C}$ & $-\mathrm{Cl}$ & $-\mathrm{SO}_{2} \mathrm{Ph}$ & $-\mathrm{SPh}$ & $-\mathrm{OPh}$ & $-\mathrm{OCH}_{3}$ \\
\hline $10^{3} \mathrm{k}_{\mathrm{A}} \mathrm{mole}^{-1} \mathrm{~s}^{-1}$ & 15 & 2067 & 5.75 & 7.67 & 2.31 & 1.25 \\
& 25 & 5259 & 9.45 & 9.60 & 2.59 & 1.39 \\
& 35 & - & 13.425 & 12.47 & 2.88 & 1.54 \\
\hline$\Delta \mathrm{H}^{\#} \mathrm{kJmol}^{-1}$ & & 2.78 & 28.83 & 15.41 & 5.74 & 5.17 \\
\hline$-\Delta \mathrm{S}^{\#} \mathrm{~J} \mathrm{~mol}^{-1} \mathrm{~K}^{-1}$ & & 221.52 & 187.22 & 231.66 & 236.91 & 243.97 \\
\hline \multicolumn{1}{c}{$\mathrm{p} K_{\mathrm{a}}$} & & 1.80 & 7.10 & 10.30 & 18.0 & 29.00 \\
\hline
\end{tabular}

The plot of $\Delta \mathrm{S}^{\#}$ versus $\Delta \mathrm{H}^{\#}$ values give straight line, except $\mathrm{X}=\mathrm{Cl}$. This indicates a common mechanism for all $\mathrm{X}$-substituent, except for the chlorine leaving group.

Actually, the second order kinetic is compatible with, Scheme 4. Therefore, the rate determining step is either the formation of Meisenhiemer intermediate $\mathbf{I}$ or the departure of the leaving group. While the first step seems to be affected by the electronic nature of the leaving group which may stabilize the ground state of the reacting compounds 2-6, the second step depends on the basicity of the leaving group X. The basicities of the leaving groups are designated by their $\mathrm{p} K_{\mathrm{a}}$ values in DMSO (Bordwel \& Hughes, 1982; Clare, Cook, Ko, Mac, \& Parker, 1966). Other effects are the steric hindrance of the bulky leaving group, the difference in the stabilization of the corresponding transition states TS and the charge polarization of the leaving group X.

The $\mathrm{k}_{\mathrm{A}}$ values for the reactions of different $\mathrm{X}$-substituent with hydrazine in DMSO gave good correlation with the leaving group basicities (not shown), except compound $2, \mathrm{X}=\mathrm{Cl}$. Although the $\mathrm{p} K_{\mathrm{a}}$ of $\mathrm{X}=-\mathrm{SO}_{2} \mathrm{Ph}(7.10)$ is smaller than that of $\mathrm{X}=\mathrm{SPh}(10.30)$, the rate constants for both are of comparable value, Table 3 . This is apparently due to (i) the steric effect which inhibits the reaction in case $\mathrm{X}=-\mathrm{SO}_{2} \mathrm{Ph}$, (ii) the intramolecular hydrogen bond in the transition state developed from the reaction of $7\left(\mathrm{X}=\mathrm{SO}_{2} \mathrm{Ph}, \Delta \mathrm{S}^{\#}=-187.22\right)$ which is less pronounced than that for the reaction of 5a $\left(X=S P h, \Delta S^{\#}=-231.66\right)$ with hydrazine. Therefore, the intramolecular hydrogen bonding in the corresponding transition states, Figure 3, is responsible for the low differences in rate constants at all temperatures, although $\mathrm{SO}_{2} \mathrm{Ph}$ is better leaving group than $\mathrm{SPh}$.<smiles>[Y]C12C=CC([N+](=O)[O-])=CC1N([TlH])[CH]N2N</smiles>

$$
\mathrm{X}=\mathrm{Cl}, \mathrm{OCH}_{3}, \mathrm{OPh}, \mathrm{SO}_{2} \mathrm{Ph}
$$

Figure 3. Intramolecular hydrogen bonding in the transition states

On the other hand, the GS stabilization of 2-6 is not responsible for increasing the rate for $\mathrm{X}=-\mathrm{SPh}$ rather than $\mathrm{X}=\mathrm{OPh}$. This is explained by the fact that the sulfur atom in compound $\mathbf{5 a}$ can resonate more than the more electronegative oxygen atom with the dinitrophenyl ring, Figure 4. Another factor which can explain the difference in rates is the charge polarization nature of the leaving group which strengths the intramolecular 
hydrogen bonding interaction.<smiles>COc1ccc([N+](=O)[O-])cc1[N+](=O)[O-]</smiles>

3

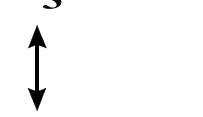

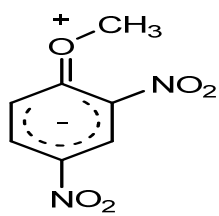<smiles>O=[N+]([O-])c1ccc(Oc2ccccc2)c([N+](=O)[O-])c1</smiles>

4<smiles>[Te][Te]</smiles><smiles>O=[N+]([O-])C1=CC(=[O+]c2ccccc2)C([N+](=O)[O-])=CC1</smiles><smiles>O=[N+]([O-])c1ccc(Sc2ccccc2)c([N+](=O)[O-])c1</smiles>

$5 a$<smiles></smiles><smiles>O=[N+]([O-])c1ccc(S(=O)(=O)c2ccccc2)c([N+](=O)[O-])c1</smiles>

6<smiles>O=[N+]([O-])c1ccc(Cl)c([N+](=O)[O-])c1</smiles>

2

Figure 4. Resonance structure of 3, 4 and 5a

Accordingly the reaction proceeds by the mechanism shown in Scheme 4 in which the departure of the leaving group in reactions of compounds 3, 4, 5a, $\mathbf{6}$ with hydrazine in DMSO at all temperatures is the rate determining step. This is clearly observed from low reactivity of compounds $\mathbf{3}$ and $\mathbf{4}$ that have the higher basicities of their leaving group anions ${ }^{-} \mathrm{OCH}_{3},{ }^{-} \mathrm{OPh}$. While, compound 2 proceeds by the same mechanism by the formation of Meisenhiemer complex II, at the rate limiting step.

\subsection{Reactions of 2,4-dinitrophenyl Aryl Sulfides 5a-i with Hydrazine in DMSO at $25^{\circ} \mathrm{C}$}

3'- and 4'-Substituted phenyl 2,4-dinitrophenyl sulfides 5a-i give the expected hydrazine derivative 7 and 4 - and 3 -substituted thiophenol or their conjugate bases on the treatment with hydrazine in almost quantitative yield, Scheme 4 . Therefore, the reactions were followed specrtophotometrically by monitoring the appearance of 7 at $\lambda$ $=(370,445 \mathrm{~nm})$.<smiles>[Y]c1cccc(Sc2ccc([N+](=O)[O-])cc2[N+](=O)[O-])c1</smiles>

5a-i<smiles>[Y]c1cccc(S)c1</smiles>

7

$$
\begin{array}{ll}
\mathbf{5 a}, \mathrm{Y}=\mathrm{H} & \mathbf{5 f}, \mathrm{Y}=4-\mathrm{Cl} \\
\mathbf{5 b},=4-\mathrm{OCH}_{3} & \mathbf{5 g}, \mathrm{Y}=3-\mathrm{Cl} \\
\mathbf{5 c}, \mathrm{Y}=4-\mathrm{CH}_{3} & \mathbf{5 h}, \mathrm{Y}=3-\mathrm{Br} \\
\mathbf{5 d}, \mathrm{Y}=3-\mathrm{OCH}_{3} & \mathbf{5 i}, \mathrm{Y}=4-\mathrm{NO}_{2} \\
\mathbf{5 e}, \mathrm{Y}=4-\mathrm{Br} &
\end{array}
$$

Scheme 4. The reactions of 2,4-dinitrophenyl aryl sulfides 5a-i with hydrazine in DMSO

All the reactions of 3'- and 4'-substituted phenyl 2,4-dinitrophenyl sulfides 5a-i with excess hydrazine obeyed pseudo-first-order kinetics. All the plots of $\mathrm{k}_{\mathrm{obsd}}$ values $v s$. hydrazine concentrations were linear, passing through the origin, indicating that the general base catalysis by a second hydrazine molecule is absent. The apparent second-order rate constants $\left(\mathrm{k}_{\mathrm{A}}\right)$ were determined from the slope of the linear plots vs. the hydrazine concentration. The $\mathrm{k}_{\mathrm{A}}$ values determined in this way are summarized in Table 4 . 
Table 4. Summary of second-order rate constants reaction constant $\rho_{\mathrm{Y}}$ and Bronsted coefficient $\beta_{\mathrm{Y}}$ for hydrazinolysis of sulfides $\mathbf{5 a}-\mathbf{i}$ in DMSO at $25^{\circ} \mathrm{C}$

\begin{tabular}{cccccccccccc}
\hline $\mathbf{c p d}$ & $\mathbf{a}$ & $\mathbf{b}$ & $\mathbf{c}$ & $\mathbf{d}$ & $\mathbf{e}$ & $\mathbf{f}$ & $\mathbf{g}$ & $\mathbf{h}$ & $\mathbf{I}$ & $\mathbf{}_{\mathbf{Y}}$ & ${ }^{\boldsymbol{\beta}} \mathbf{Y}$ \\
\hline $\mathbf{Y}$ & $\mathbf{H}$ & 4-OMe & 4-Me & $\mathbf{3 - O M e}$ & $\mathbf{4 - B r}$ & $\mathbf{4 - C l}$ & $\mathbf{3 - C l}$ & $\mathbf{3 - B r}$ & $\mathbf{4 N O}_{\mathbf{2}}$ & - & - \\
\hline $\begin{array}{c}\mathbf{1 0}^{3} \mathbf{k}_{\mathbf{A}} \\
\mathbf{~ m o l}^{\mathbf{1}} \mathbf{s}^{\mathbf{1}}\end{array}$ & 9.60 & 6.05 & 7.14 & 13.46 & 16.24 & 16.34 & 23.03 & 23.16 & 61.4 & 0.95 & - \\
\hline $\mathbf{p} \boldsymbol{K}_{\mathbf{a}}$ & 10.28 & 11.19 & 10.82 & - & 8.98 & - & 8.57 & & 5.5 & - & 0.18 \\
\hline
\end{tabular}

The reactivity of 6a-i increases as the substituent $Y$ on the leaving group becomes a stronger electron-withdrawing group, Table 4. The $\mathrm{k}_{\mathrm{A}}$ value for the reactions of 5a-i with hydrazine in DMSO increases from $6.05 \times 10^{-3}$ to $61.40 \times 10^{-3}$ as the substituent $\mathrm{Y}$ changes from 4- $-\mathrm{OCH}_{3}$ to $4-\mathrm{NO}_{2}$. This is consistent with a typical nucleophilic substitution reaction (Crampton et al., 2006; Smith, 2001) provided there is a positive charge developed at the nucleophilic nitrogen atom and a negative charge at the thiophenoxy sulfur atom in the transition state.

The Hammett plots have long been considered to be the most commonly employed linear free energy relationship (LFER) to examine structure-reactivity relationships for aromatic substrates and in investigation of reaction mechanism. It is found that $\sigma^{-}$-constants give good Hammett correlation against $\log \mathrm{k}_{\mathrm{A}}$ with $\rho=0.65(\mathrm{r}=0.99)$. It implies that the sulfur atom in thioaryloxide bears a partial negative charge which can be delocalized on substituent $\mathrm{Y}$ in the transition state. This suggests that the leaving group departure occurs at the rate-determining step.

The reaction constant value $\left(\rho_{Y}=0.65\right)$, seems to indicate that the substituent effect is not high. The low value of $\rho$ in this study is in contrast to the previously reported value $(\mathrm{ca}+4)$ for substituted halogenonitrobenzene because their substituents affect directly the reaction center (Chaw, Fischer, \& Happer, 1971), while, the present substituents exist in the leaving group moiety. Therefore, our results clearly suggest that the reaction of compounds 5a-i proceed through an $\mathrm{S}_{\mathrm{N}} \mathrm{Ar}$ mechanism in which the leaving group departure from the zwiterionic complex intermediate occurs in the rate-determining step, Scheme 4.

\subsection{Bronsted Relationship}

Bronsted relationship has been used as a probe for determining the mechanistic pathway (Mohanty \& Nayak, 1975). The magnitude of the Bronsted coefficient has usually been related to the extent of bond formation in the transition state (Senator, Ciuffarin, \& Fava, 1970). The sign of $\beta$ depends on the $\mathrm{p} K_{\mathrm{a}}$ either for the attacking nucleophile or the leaving group. As the $\mathrm{p} K_{\mathrm{a}}$ of the nucleophile varies at constant leaving group a positive Bronsted coefficient is observed (Ananthakrishnanadar \& Kannan, 1982). This can be explained by the direct proportionality between the logarithmic of the rate and the $\mathrm{p} K_{\mathrm{a}}$ of the nucleophile (i.e., the higher the $\mathrm{p} K_{\mathrm{a}}$ value of the nucleophile, the higher the rate of the reaction). Generally, Bronsted coefficients between 0.6 and 1.5 have been taken as indicative of extensive bond formation whereas those between 0.0 and 0.3 are indicative of the little bond formation when the $\mathrm{p} K_{\mathrm{a}}$ of the nucleophiles are variable (Ananthakrishnanadar \& Kannan, 1982). On the other hand, the change of the $\mathrm{p} K_{\mathrm{a}}$ values of the leaving group at constant nucleophile would result in a negative Bronsted coefficient (Khattab et al., 2011) due to the inverse proportionality between $\mathrm{p} K_{\mathrm{a}}$ of the leaving group and the rate (i.e., the higher the $\mathrm{p} K_{\mathrm{a}}$ of the leaving group, the lower the rate).

Table 4 shows that the reactivity of 2,4-dinitrophenyl phenyl sulfide derivatives $\mathbf{5 a - i}$ and hydrazine increases with the decrease in $\mathrm{p} K_{\mathrm{a}}$ of the thioaryl leaving group (Dean, 2003). The correlation of the rate constants against $\mathrm{p} K_{\mathrm{a}}$ values of the corresponding conjugate acids in DMSO gives small $\beta_{\mathrm{lg}}$ value $(-0.18, \mathrm{r}=0.99)$. This is consistent with the good Hammett correlation using $\sigma^{-}$-constants. Accordingly, the reaction of 5a-i proceeds through zwitterionic intermediate in which bond formation to the nucleophile is well advanced and bond rapture to the leaving group has proceeded in a slow extent in the transition state.

\section{Conclusion}

The reaction of 2,4-dinitrophenyl acetate with hydrazine in $\mathrm{MeOH}$ proceeds exclusively through acyl-oxygen scission. The reaction obeyed pseudo-first-order rate constants $\left(k_{\mathrm{obs}}\right)$ and the large negative $\Delta \mathrm{S}^{\#}$ value indicates a rigid transition state or great participation of methanol molecules in the activated complex. The leaving group departs slowly in a concerted mechanism due the large negative $\Delta \mathrm{S}^{\#}$ value, the lower value of the $\mathrm{p} K_{\mathrm{a}}$ of the conjugate acid of the leaving group than that of the hydrazine, and the basicity of the incoming amines and the leaving groups are the same.

The reactions of 1-chloro-2,4-dinitrobenzene with hydrazine in $\mathrm{MeOH}, \mathrm{MeCN}$ and DMSO at different 
temperatures were followed spectrophotometrically. Kinetic results suggest that the reaction proceeds by uncatalysed process with the rate determining formation of the zwitterionic intermediate. The plot of $\Delta \mathrm{H}^{\#}$ against $\log -\Delta S^{\#}$ indicates a common mechanism for the reaction in these solvents. The reactivity sequence for the reactions of 1-chloro-2,4-dinitrobenzene with hydrazine is the order DMSO $>\mathrm{MeCN}>\mathrm{MeOH}$. This order depends on the intramolecular and intermolecular hydrogen bonding interactions. Reactions of 1-methoxy2,4-dinitrobenzene, 2,4-dinitrophenyl phenyl ether, 2,4-dinitrophenyl phenyl sulfide and 2,4-dinitrophenyl phenyl sulfone with hydrazine in DMSO show absence of general base catalysis by a second hydrazine molecule The plot of $\Delta \mathrm{S}^{\#}$ versus $\Delta \mathrm{H}^{\#}$ values give straight line, except for $\mathrm{X}=\mathrm{Cl}$, which indicates a common mechanism for all X-substituent, except for the chlorine leaving group. The reaction proceeds by the mechanism in which the departure of the leaving group at all temperatures is the rate determining step. The mechanism is compatible with the second order kinetic, the electronic nature of the leaving group, the basicities of the leaving groups and the steric effects of the bulky leaving group, the difference in the stabilization of the corresponding transition states TS and the charge polarization of the leaving group X.

Reactions of 2,4-dinitrophenyl aryl sulfides with hydrazine in DMSO at $25{ }^{\circ} \mathrm{C}$ were followed specrtophotometrically and proceeds by a typical nucleophilic substitution reaction uncatalysed process. The reactivity increases as the substituent on the leaving group becomes a stronger electron-withdrawing group. The linear plot of $\sigma^{-}$-constants gives good Hammett correlation against $\log \mathrm{k}_{\mathrm{A}}$ with $\rho=0.65$ suggesting that the leaving group departure occurs at the rate-determining step and the substituent effect is not high. The correlation of the rate constants against $\mathrm{p} K_{\mathrm{a}}$ values of the corresponding conjugate acids in DMSO gives small $\beta_{\mathrm{lg}}$ value $(-0.18)$ which indicates that the reaction proceeds through zwitterionic intermediate in which bond rapture to the leaving group has proceeded in a slow extent in the transition state.

\section{References}

Ahmad, F., Qureshi, P. M., \& Andrabi, S. M. A. (1995). Kinetic method of analysis for an important pharmaceutical 2,4-dinitrophenylhydrazine. Anal. Proc., 32, 61-63. http://dx.doi.org/10.1039/ai9953200061

Ahmed, A. M., Hamed, E. A., El-Bardan, A. A., \& Saad, E. F. (1989). Effect of diaryl sulfides and sulfones on the rate of production of electrolytic copper powder. Alex. Eng. J., Alex. Univ., 28, 577-591.

Al-Howsaway, H. O. H., Fathalla, M. F., El-Bardan, A. A., \& Hamed, E. A. (2007). Reaction of 4-chloro-3,5-dinitrobenzotrifluoride with Aniline derivatives. Substituent effects. J. Chem. Res., 509-512.

Ananthakrishnanadar, P., \& Kannan, N. (1982). Kinetics of reaction of picryl bromide with substituted biphenyl-4-carboxylate ions. J. Chem. Soc., Perkin Transactions 2, 1305-1308.

Annulli, A., Mencareli, P., \& Stegel, F. (1984). Nucleophilic aromatic substitution in the pyrrole ring: leaving group effect. J. Org. Chem., 49, 4065-4067. http://dx.doi.org/10.1021/jo00195a040

Asghar, B. H. M., Fathalla, M. F., \& Hamed, E. A. (2009). Solvent and substituent effects on the reaction of 2and 4-chloro-3,5-dinitrobenzotrifluorides with substituted anilines. Int. J. Chem. Kinet., 41, 777-786. http://dx.doi.org/10.1002/kin.20455

Bartoli, G., \& Todesco, P. E. (1977). Nucleophilic aromatic substitution: linear free relationships between reactivity and psysical properties of leaving group and substrates. Acc. Chem. Res., 10, 125-132. http://dx.doi.org/10.1021/ar50112a004

Bernasconi, C. F., \& Schmid, P. (1967). Base catalysis of the reaction of morpholine with 2,4-dinitrophenyl phenyl ether in 10 percent dioxane-90 percent water. J. Org. Chem., 32(10), 2953-2956. http://dx.doi.org/10.1021/jo01285a003

Bordwel, F. G., \& Hughes, D. L. (1982). Thiol acidities and thiolate ion reactivities toward butyl chloride in dimethyl sulfoxide solution. The question of curvature in Broensted plots. J. Org. Chem., 47, 3224-3232. http://dx.doi.org/10.1021/jo00138a005

Bunnett, J. F., \& Davi, G. T. S. (1954). Kinetics of Reactions of 2,4-Dinitrochlorobenzene with some familiar Nucleophilic Reagents. J. Am. Chem. Soc., 76, 3011-3015. http://dx.doi.org/10.1021/ja01640a044

Bunnett, J. F., Garbisch, E. W., \& Pruitt Jr., K. M. (1957). The "Element Effect" as a Criterion of Mechanism in Activated Aromatic Nucleophilic Substitution Reactions. J. Am. Chem. Soc., 79, 385-391. http://dx.doi.org/10.1021/ja01559a040

Bunnett, J. F., \& Davi, G. T. S. (1960). The Mechanism of Aminolysis of Esters. J. Am. Chem. Soc., 82, 665-674. http://dx.doi.org/10.1021/ja01488a043 
Chaw, Z. S., Fischer, A., \& Happer, D. A. R. (1971). Rates of base-catalysed hydrolysis of substituted aryl benzoates. J. Chem. Soc. (B), 1818-1819. http://dx.doi.org/10.1039/j29710001818

Clare, B. W., Cook, D., Ko, E. C. F., Mac, Y. C., \& Parker, A. (1966). Solvation of Ions. IX. ${ }^{1}$ The Effect of Anion Solvation on Acid Dissociation Constants in Methanol, Water, Dimethylformamide, and Dimethyl Sulfoxide. J. Am. Chem. Soc., 88, 1911-1916. http://dx.doi.org/10.1021/ja00961a012

Crampton, M. R., Emokape, T. A., Howard, J. A. K., Isanbor, C., \& Mondal, R. (2004). Leaving group effects on the mechanism of aromatic nucleophilic substitution $\left(\mathbf{S}_{\mathrm{N}} \mathrm{Ar}\right)$ reactions of some phenyl 2,4,6-trinitrophenyl ethers with aniline in acetonitrile. J. Phys. Org. Chem., 17, 65-70. http://dx.doi.org/10.1002/poc.690

Crampton, M. R., Emokape, T. A., \& Isanbor, C. (2006). Electronic and steric effects in the $\mathbf{S}_{\mathrm{N}} \mathrm{Ar}$ substitution reactions of substituted anilines with 2,4-dinitrophenyl 2,4,6-trinitrophenyl ether in acetonitrile. J. Phys. Org. Chem., 19, 75-80. http://dx.doi.org/10.1002/poc.997

Crampton, M. R. ,T. A., Emokpae, C., Isanbor, Batsanov, A. S., Howard, J. A. K., \& Mondal, R. (2006). Effects of ortho- and para-Ring Activation on the Kinetics of $\mathrm{S}_{\mathrm{N}} \mathrm{Ar}$ Reactions of 1-Chloro-2-nitro and 1-Penoxy-2-nitrobenzenes with Aliphatic Amines in Acetonotrile. Eur. J. Org. Chem., 5, 1222-1230. http://dx.doi.org/10.1002/ejoc.200500774

Crampton, M. R., Emokape, T. A., \& Isanbor, C. (2007). The Effects of Ring Substituents and Leaving Groups on the Kinetics of $\mathrm{S}_{\mathrm{N}} \mathrm{Ar}$ Reactions of 1-Halogeno- and 1-Phenoxy-nitrobenzenes with Aliphatic Amines in Acetonitrile. Eur. J. Org. Chem., 1378-1383.

Dawson, R. M. C. (1989). Data for Biochemical Research. Oxford Clarendon Press.

Dean, A. J. (2003). Lange's Handbook of Chemistry. McGraw Hill Companies Inc.

Edwards, J. O., \& Pearson, R. G. (1973). Hard and soft Acids and Bases.

El-Hegazy, F. El. M., Abdel-Fathah, S. Z., Hamed, E. A., \& Sharaf, S. M. (2000). Kinetics of the reaction of 2-chloro-3,5-dinitropyridine with meta- and para-substituted anilines in methanol. J. Phys. Org. Chem., 13, 549-554. http://dx.doi.org/10.1002/1099-1395(200009)13:9<549::AID-POC297>3.0.CO;2-5

El-Mallah, N. M., Nabil, G. M., Senior, S. A., Ramadan, M. Sh., \& Hamed, E. A. (2010). Effect of Acetonitrile-Water Mixtures on the Reaction of Dinitrochlorobenzene and Dinitrochlorobenzotriflouride with Hydroxide Ion. Int. J. Chem. Kinet., 42, 453-463. http://dx.doi.org/10.1002/kin.20495

Emokape, T. A., \& Atasie, N. V. (2005). The influence of some steric and electron effects on the mechanism of aromatic nucleophilic substitution $\left(\mathrm{S}_{\mathrm{N}} \mathrm{Ar}\right)$ reactions in nonpolar solvent. Int. J. Chem. Kinet., 37, 744-750. http://dx.doi.org/10.1002/kin.20109

Fathalla, M. F., Ibrahim, M. F., \& Hamed, E. A. (2004). Kinetics of alkaline hydrolysis of 2-thioaryl-3,5-dinitropyridine derivatives in 50\% v/v DMSO-Water. J. Chem. Res., 150-151.

Fathalla, M. F., \& Hamed, E. A. (2006). Kinetics of the reaction between methyl-2,4-dichloro-3,5-dinitrobenzoate and piperidine, piprazine, morpholine and thiomorpholine in methanol and benzene. J. Chem. Res., 413-416.

Fathalla, M. F., Kassem, T. S., \& Hamed, E. A. (2008). Kinetics of the reaction between methyl-2,4-dichloro-3,5-dinitro benzoate and piperidine: Solvent Effect. Ind. J. Chem., Sect., 47A, 1348-1354.

Ibrahim, M. F., Senior, S., El-Atawy, M. A., El-Sadany, S. K., \& Hamed, E. A. (2011). DFT calculations of 2,4,6-trinitrophenylbenzoate derivatives: Structure, ground state properties and spectral properties. J. Mol. Struct., 1006, 303-311. http://dx.doi.org/10.1016/j.molstruc.2011.09.024

Guanti, G., Dell'Erba, C., \& Pero, F. (1975). Acyl-O versus aryl-O bond scission in reactions of benzenethiolate with nitrophenyl esters of carboxylic acids. Chem. Comm., 823-824.

Guanti, G., Dell'Erba, C., Pero, F., \& Leandri, G. (1977). Acyl-oxygen versus aryl-oxygen bond scission in reactions of benzenethiolate with nitrophenyl esters of carboxylic acids. J. Chem. Soc., Perkin Trans. 2, 966-970.

Guanti, G., Dell'Erba, C., Pero, F., \& Cevasco, G. (1978). Polar effects in nucleophilic substitutions at aromatic and carbonyl carbon atoms. Kinetics of the reactions of substituted arenethiolates with 2,4-dinitrophenyl acetate and benzoate. J. Chem. Soc., Perkin Trans. 2, 422-425. http://dx.doi.org/10.1039/p29780000422

Hall Jr., H. K. (1957). Correlation of the Base Strengths of Amines. J. Am. Chem. Soc., 79, 5441-5444. http://dx.doi.org/10.1021/ja01577a030 
Hamed, E. A. (1997a). Nucleophilic substitution at the pyridine ring. Kinetics of the reaction of 2-chloro-3,5-dinitropyridine with arylthiolates in methanol. Int. J. Chem. Kinet, 29, 515-521. http://dx.doi.org/10.1002/(SICI)1097-4601(1997)29:7<515::AID-KIN5>3.0.CO;2-X

Hamed, E. A. (1997b). Nucleophilic Substitutions at the Pyridine Ring: Kinetics of the Reaction of 2-Chloro-3-Nitro and 2-Chloro-5-Nitropyridines with piperidine and Morpholine in Methanol and Benzene. $\begin{array}{lllll}\text { Int. } & \text { J. Chem. }\end{array}$ http://dx.doi.org/10.1002/(SICI)1097-4601(1997)29:8<599::AID-KIN5>3.0.CO;2-P

Hamed, E. A., El-Bardan, A. A., Saad, E. F., Gohar, G. A., \& Hassan, G. M. (1997). Nucleophilic Substitution at the pyridine ring. Conformational preference of the products and kinetics of the reactions of 2-Chloro-3Nitro and 2-Chloro-5-Nitropyridines with Arenethiolates. J. Chem. Soc., Perkin Trans. 2, 2415-2421. http://dx.doi.org/10.1039/a701902e

Isanbor, C., \& Babatunde, A. I. (2009). Kinetics of $\mathrm{S}_{\mathrm{N}} \mathrm{Ar}$ reactions of 1-phenoxy-nitrobenzenes with aliphatic amines in toluene: ring substituent and solvent effects on reaction pathways. J. Phys. Org. Chem., 22, 1078-1085. http://dx.doi.org/10.1002/poc.1562

Khattab, Sh. N., Hassan, S. Y., Hamed, E. A., \& El-Faham, A. (2007). Synthesis and morpholinolysis of N,N-Diethyl Carbamate Derivatives of 4-HOAt, 7-HOAt and HOBt. J. Chem. Research., 247-251.

Khattab, Sh. N., Hamed, E. A., Albericio, F., \& El-Faham, A. (2011). Synthesis and Aminolysis of 2,4-Dinitrophenyl and 5-Nitropyridine $N$-Hydroxy Oxime Derivatives. Bull. Chem. Soc. Jpn., 84, 633-639. http://dx.doi.org/10.1246/bcsj.20110015

Kirsch, J. F., Clewell, W., \& Simon, A. (1968). Multiple structure reactivity correlations. Alkaline hydrolyses of acyl and aryl-substituted phenyl benzoates. J. Org. Chem., 33, 127-132. http://dx.doi.org/10.1021/jo01265a023

Konasiewicz, A. K., \& Maccoll, A. (1964). The methanolysis of nitrophenyl esters. Part I. The kinetics of the transesterification of picryl acetate and benzoate. J. Chem. Sec., 1267-1274.

Macini, P. M., Fortunato, G. G., Adam, C., Vottero, L. R., \& Terenzani, A. J. (2002). Specific and non-specific solvent effects on aromatic nucleophilic substitution. Kinetics of the reaction of 1-fluoro-2,6-dinitrobenzene and homopiperidine in binary solvent mixtures. J. Phys. Org. Chem., 15, 258-269. http://dx.doi.org/10.1002/poc.476

Macini, P. M., Fortunato, G. G., \& Vottero, L. R. (2004). Kinetics of the reactions between 1-fluoro-2,6-dinitrobenzene and pyrrolidine and piperidine in binary solvent systems: Influence of the nucleophile structure. J. Phys. Org. Chem., 17, 138-147. http://dx.doi.org/10.1002/poc.704

Menger, F. M., \& Smith, J. H. (1972). Mechanism of ester aminolyses in aprotic solvents. J. Am. Chem. Soc., 94, 3824-3829. http://dx.doi.org/10.1021/ja00766a027

Mohanty, T. R., \& Nayak, P. L. (1975). Kinetics of the reactions of picryl chloride with substituted benzoate ions. J. Chem. Soc., Perkin Trans. 2, 242-244.

Nyburg, S. C., Faerman, C. H., Prasad, L., Palleros, D., \& Nudelman, N. (1987). Structures of 2,4-dinitroanisole and 2,6-dinitroanisole. Acta Cryst., C43, 686-689. http://dx.doi.org/10.1107/S0108270187094514

Paghaleh, J. J., Harifi-Mood, A. R., \& Gholami, M. R. (2011). Reaction kinetics investigation of 1-fluoro-2,4-dinitrobenzene with substituted anilines in ethyl acetate-methanol mixtures using linear and nonlinear free energy relationships. J. Phys. Org. Chem., 24, 1095-1100. http://dx.doi.org/10.1002/poc.1861

Saad, E. F, Hamed, E. A., \& EL-Bardan, A. A. (1991). Skeletal Rearrangements in 2,4-dinitrophenyl-4'-substituted Phenyl Sulfides and Sulfones Upon Electron Impact. Spectroscopy letters, 24, 413-421. http://dx.doi.org/10.1080/00387019108020666

Senator, L., Ciuffarin, E., \& Fava, A. (1970). Timing of bond formation and breaking in nucleophilic substitution at dicoordinate sulfur. Effect of the basicity of entering and leaving groups in the reaction of oxygen nucleophiles with para-substituted phenyl sulfenate esters. J. Am. Chem. Soc., 92, 3035-3039. http://dx.doi.org/10.1021/ja00713a019

Smith, M. B. (2001). J. March, March's Advanced Organic Chemistry (5th ed., p. 860). New York: John Wiley.

Stirling, C. J. M. (1979). Leaving groups and nucleofugality in elimination and other organic reactions. Acc. Chem. Res., 12, 198-203. http://dx.doi.org/10.1021/ar50138a002 
Terrier, F. (1991). Nucleophilic Aromatic Displacement. The Influence of the Nitro Group. New York: VCH.

\section{Copyrights}

Copyright for this article is retained by the author(s), with first publication rights granted to the journal.

This is an open-access article distributed under the terms and conditions of the Creative Commons Attribution license (http://creativecommons.org/licenses/by/3.0/). 